\title{
Pathologia da surdo mudez
}

No estudo da pathologia da surdez, nos limitaremos a resumir o mais claramente possivel, as innumeras leituras que temos sobre o. assumpto, pois absolutamente nos falta competencia e material para procedermos qualquer estudo deste genero. Faremos o possivel para. sermos breve, precisos e concisos, apresentando o que ha de mais. moderno ie interessante nesta complicada questão da pathologia da surdo mudez.

Este estudo tem tomado nestes ultimos annos orientação nova, devido a novios e mais delicados processos de exame microscopico do ouvido, principalmente das cavidades labyrinthicas, cuja pathologia: ainda está muito pouco esclarecida e muito controvertida; se alguma cousa ha estabelecida em relação ao vestibulo e aos canaes semi-circulares, muito pouco, quasi nada, ha em relação a cochlea, que parece ser o verdadeiro orgão da audição.

De accordo com as lesões anatomo pathologicas, divideremlos preliminarmente os casos de surdo mudez - 1) devido a perturbações do desenvolvimento, 2) devido a traumatismos e causas infeccioșas.

\section{I}

\section{SURDO MUDEZ DEVIDA A PERTURBAÇŌES,DO DESENVOLVIMENTO.}

Sempre de accordo coml a natureza das lesões natomo pathologicas encontradas, dividiremos esta forma de surdo mudez, que representa o verdadeiro typo da surdo mudez congenita, em 3 typos:

a) Surdo mudez devida a thyroidite endemica.

b) Surdo mudez congenita esporadica.

c) Surdo mudez devida a malformações congenitas, affectando a cochlea e o apparelho vestibular.

a) SURDO MUDEZ DEVIDA A THYROIDITE ENDEMICA: 
Os individuos portadores desta forma de surdo mudez, com raras excepç̃ôes, são debeis mentaes, candidatos a demencia ou a idiotia. O bocio raramente se apresenta no paciente, mas com frequencia extraordinaria o notamos em outros membros da familia, principalmente na linha directa dos ascendentes. A maior parte destes indivi"duos já apresentam a surdez ao nascimento.

Alguns auctores, como Nagg e Siebenmann, acham que esta causa isolada não seria sufficiente para produzir a surdo mudez, mas simplesmente uma mouquidão mais ou menos accentuada; a debilidade mental, é que complicando-a, acarretaria a surdo mudez. Cuidadosas provas de audição realizadas nestes individuos, demonstraram que em cerca de $25 \%$ delles a audição é normal, em $45 \%$ ha apenas leve surdez, em $25 \%$ surdez accentuada, e apenas em $5 \%$ surdez total.

Em regra geral encontramos outras perturbações de desenvolvimento physico ou intellectual. Segundo Wirchow as principaes alterações seriam encontradas na conformação da craneo: abaixamjento. e encurtamento do esphenoide, e outras modificações da base do craneo; estas alterações do desenvolvimento da base do craneo, acarretariam deformações da aboboda craneana, que por sua vez acarretariam perturbações no desenvolvimento do cerebro, e um desvio na formação e na posição dos ossos da face. Encontramos muito frequentemente nestes casos, a diminuião da circumferencia crảneana, bem como uma diminuição do diametro antero posterior, em relação ao transversal do craeno.

Pathologia - Ouvido medio: As alterações que ahi encontramos são importantes. Alexander menciona o espessamento myxomatoso dos tecidos sub mucosos de revestimento do ouvido medio. $\mathrm{Na}$ maioria dos casos, mas não em todos, as janellas labyrinthicas achamse obstruidas por tecido conjunctivo e cellulas de gordura. A apophyse longa da bigorna e a cabeça do estribo podem estar adherentes ao canal do facial por tecido conjunctivo ou mesmo osseo. Com muita frequencia encontramos a ankylose da base do estribo na janella oval, e exostoses sobre o promontorio ,não sendo raros os casos em que este se apresenta inteiramente tomado por um processo de osteo porose. O tympano apresenta-se calcificado em muitos casos. Em alguns outros foram constatadas alterações inflammatorias no ouvido medio, certamiente vestigios de antigas otites medias suppuradas. 
A capsula do labyrintho frequentemente se apresenta espessada e esclerosada.

São insignificantes as alterações encontradas no ouvido interno: ligeiras degenerações do orgão de Corti e no ganglio espiral Alexander). Em muitos casos o ouvido interno tem sido encontrado. perfeitamente normal.

Resumindo, poderemos dizer que a surdo mudez devida a thyroidite endemica é caracterisada por alterações do ouvido medio e da capsula labyrinthica, incluindo as janellas, emquanto o ouvido interno se apresenta quasi sempre normal.

Alguns observadores acreditam que as alterações de desenvolvimento nestes casos, sejam causadas por uma anomalia constitucional congenita. A dureza de ouvido seria devida a alterações do ouvido medio, emquanto que a completa surdez só adviria mais tarde com a atrophia do labyrintho. Outros investigadores pensam que as 'alterações principaes são no cerebro, dependentes de perturbações da secreção thyroidéa; que tambem seria a causa de alterações na ossificação do ouvido.

b) SURDO MUDEZ CONGENITA E ESPORADICA.

1 - Casos de aplasia de todo o labyrintho. O caso typico desta. forma de surdo mudez foi descripto por Michel, que encontrou 0 , conducto auditivo externo e a membrana tympanica normaes, a cavidade tympanica muito pequena, e ausencia de ambos os labyrinthos. Siebenmann explica esta condição pela ausencia da vesicula otica no primeiro mez de vida fetal. Alguns auctores negam isto e explicam a ausencia do labyrintho por uma classificação total secun-daria, devida a processos inflammiatorios.

2 - Casos em que o labyrintho osseo e membranoso apresentam-se affectados (casos de Mondini e Alexander). Na maioria destes casos, os pacientes são completamente surdos, raramente se encontrando restos de audição. Encontramos sempre o ouvido externo. e o medio normaes. No caso de Mondini toda a capsula ossea da cochlea estava destruida, havendo sido encontrada a disposição nornal da escala auditiva sómente em sua parte mais baixa; na parte alta havia um grande espaço vasio. Alexander pensa que esta anomialia seja devida a uma parada do desenvolvimento durante o segundo e terceiro mez de vida intrauterina. $O$ ducto cochlear pode se apre- 
sentar dilatado ou collapsado, havendo ausencia do orgão de Corti em muitos logares; em outros casos o orão de Conti conserva a sua forma embryonaria, que consiste em uma carreira de cellulas epitheliaes não differenciadas, collocada verticalmenlte sobre a membrana basilar." No caso de Alexander o ganglio espiral do nervo coclhear não tomava um curso espiral, como deveria ser, achando-se collocado centralmente no modiolus. Alexander encontrou atrophia da macula, da saccula e da utricula. No caso de Mondini o aqueducto era dilatado, e fechado em sua parte posterior por uma membrana; o sacco endolymphatico era muito grande e repleto de liquido.

\section{c) SURDO MUDEZ DEVIDA A MALFORMAÇŌES CON- GENITAS AFFECTANDO TANTO O APPARELHO COCHLEAR COMO O VESTIBULAR.}

O typo clinico desta forma de surdo mudez é frequentemente associado a retinite pigmentosa. Leber encontrou em cerca de $20 \%$ dos casos de retinite pigmentosa, perturbações acusticas. A retinite pigmentosa é. hereditaria. Nas familias que a tem; costuma-se encontrar perturbações auditivas mesmo nos individuos que não soffrem daquelle mal. Bezold examinando 2 doentes com retinite pigmentosa constatou a surdez em um ouvido de um delles, emquanto o outro, e ambos do outro doente, apresentavam falhas de audição. Frey e Hammerschlag fizeram constatações semelhantes em. outros 4 casos destes 2 eram debeis mientaes, 2 tinham irmãs e irmãos surdos e imbecis, e em todos elles verificaram a ausencia de reacção rotatoria. Siebenmann e Bing verificaram um caso de um surdo-mudo que tinha 4 irmãos apparentemente surdos de nascença, e um irmão portador de retinite pigmentosa. $\mathrm{E}$ ' interessante notar ainda que em casos de retinite pigmentosa unilatêral, tem-se constatado tambem a surdez unilateral, do lado da vista atacada. Além da retinite pigmentosa são frequentes nestes surdos mudos outras anomalias oculares taes como distribuição defeituosa dos vasos sanguineos do fundo do olho, o crescente para baixo, astigmatismo irregular, e o chamado fundo de olho albinotico, isto é, falta de pigmento no esitroma.

Pathologia: No apparelho vestibular, Siebenmann e Bing encontraram a macula e. a crista degeneradas, conservando-se porem 
normal o resto do apparelho vestibular. Em dois casos de Oppikofer foi constatada a atrophia do nervo vestibular e do respectivo ganglio.

$\mathrm{Na}$ cochlea, Nager constatou o ducto cochlear dilatado ou collapsado ,e o epithelio sensorial ausente ou mal desenvolvido. Alguns auctores encontraram o ganglio espiral e o nervo cochlear muito atrophiados, uma pobresa extrema de vascularisação das terminações nervosasa na cochlea e no vestibulo, alterações esta correspondente as alterações pathologicas encontradas na retinite pigmentosa.

Para vo lado de cerebro, Bing notou placas de esclerose na arteria basilar e no circulo de Willis, e atrophia das 3 primeiras circumvoluções, principalmente do lado esquerdo, e signaes de endoarterite nos vasos.

1 - Degeneração sacculo cochlear typo de Scheibe. Alexander é de opinião que $70 \%$ dos casos de surdo mudez congenita pertence ma este grupo sacculo cochlear, na qual a utricula e os canaes semicirculares estão intactos. Geralmente existem resstos de audição e o apparelho vestibular reage normalmente as provas calorica e rotatoria.

Nestes casos, em regra geral não observamos alterações do ouvido medio. O labyrintho osseo apresenta-se commumente normal (Lindt cita um caso em que ahi encontroụ um fóco de oto-esclerose). Os espaços do labyrintho osseo apresentam-se dilatados, e em grande numero de casos encontra-se a saccula collapsada e o ductus reuniens obliterado. São rarissimos os casos em que a saccula é normal. O canal cochlear pode se apresentar dilatado ou estreitado, ou ainda, o que é mais commum, dilatado em umas partes e estreitaldo em outras. Se o canal é estreitado a membrana de Reissner commumente adhere aos restos do orgão de Corti ou a membrana basilar.. O orgão de Corti pode estar ausente em parte ou irreconhecivel. A membrana tectoria apresenta-se geralmente recoberta por um epithelio e rebatida contra o sulco espiral. Em outros casos a membrana tectoria é rebatida da escala media contra a estria vascularis. Esta pode estar ausenite ou substituida por um epithelio chato, podendo ainda formar uma excrecencia polypoide da escala media. Estas anormalidades podem ser explicadas pela falta de desenvolvimento ou então por uma fraqueza hereditaria do ouvido.

2 - Pressão augmentada na perilympha ou na endolympha, Gray é de opinião que a dilatação dos espaços labyrinthicos seja de- 
vida ao augmento da pressão intracraneana e peri lymphatica durante a vida fetal o upouco depois do nascimento. A dilatação do canal. cochlear seria devida ao augmento da secreção da endo lympha pela. estria vascularis que é um orgão secretor.

3 - Alterações inflamatorias - Diversos autcores pensam que estas alterações sejam causadas pela meningite ocorrida na vida intra uterina. Siebmann menciona como exemplo a infecção placentaria. como causa da meningite. Recorda u mcaso de uma mulher gravida ide 7 mezes, na qual appareceu dor no ouvido esquerdo, rapidamente seguida de coma, sendo constatados signaes de meningite. De facto, a autopsia revelou meningite da base. $O$ feto tambem mostrou na. autopsia meningite séro purulenta. O liquido cephalo rachidiano de: ambos apresentava o diplococcus intra cellular, e este mesmo germen foi separado em cultura pura do ouvido esquerdo da mãe. Herzoy diz já ter conseguido uma meningite experimental, dizendo ter encontrado no labyrintho lesões analogas aquellas de surdo mudez congenita.

4 - Surdo mudez congenita e oto esclerose - Em alguns casos. de surdo mudez congenita foram encontrados focos de oto esclerose. na capsula do labyrintho .Desta observação, Alexander lançou a hypothese de hảver um traço de união entre a surdez congenita e oto esclerose. Manasse tambem demonstrou que nos casos de oto esclerose antiga, as lesões encontradas no nervo auditivo, muito se assemelham áquellas encontradas em casos de surdez de origem nervosa. Gaerke entrentanto é de opinião que a oto esclerose ahi nesses casos. não é mais que um miéro accidente de importancia muito relativa. Hamniersclhag, considera a surdez hereditaria e a oto esclerose como uma só molestia, por serem ambas de origem degenerativa.

\section{SURDO MUDEZ ASSOCIADA A ALTERAÇŌES NO CEREBRO}

Castex acredita que a surdo mudez seja devida a lesões concomitantes do cortex cerebral e do ouvido, julgando elle que as alterações cerebraes sejam sempre devidas a meningite adquirida na vi. da intra uterina. 


\section{SURDO MUDEZ ADQUIRIDA OU INFLAMATORIA}

A pathologia da surdo mudez adquirida é uma questão relativa. mente simples. E' a propria pathologia das labyrinthites occurrentes durante a vida intra uterina ou post natal.

A labyrinthite é quasi sempre de natureza meningitica.

De outro lado a labyrinthite post-natal pode ser occasianada 1) por traumatismo ou fractura da base do craneo, 2) por uma otite media com invasão do labyrintho atravez da janella redonda ou. oval, ou atravez do promontorio formado pela saliencia do canal semi-circular externo, 3) por lepto meningites purulentas com infecção do ouvido interno propagada ou ao lọngo das fibras do VIII par ou ao longo do aqueducto da cochlea. Alguns annos depois da occurrencia da surdez, torna-se difficil ou mesmo impossivel, deter: minar o exacto caminho da infecção.

1 - Surdo mudez devida a traumatismo: E' sempre conséquente: a fractura da base do craneo, attingindo o labyrintho de ambos os lados. Cerca de $4 \%$ dos casos de surdo mudez adquirida são de origem traumatica. Pelo exame microscopico podemos quasi sempre notar vestigios de umia fractura remota.

Os canaes semi circulares apparecem quasi sempre cheios por tecido conjunctivo ou osseo néo-formado, sendo que estè pròcesso. attinge com igual intensidade a todos os canaes. A sutricula e a saccula apresentam-se dilatadas. O ducto cochlear pode se apresentaı cheio de tecido conjunctivo ou osseo néo-formado, que se accumila principalmente nos espaços peri lymphaticos; em alguns casos notta. mos o ducto cochlear bastante dilatado. O neuro epithelio da cochlea bem como o ganglio espiral apresentam-se atrophiados e degenerados.

2 - Surdez devida a labyrinthite secundaria à otite media süp. purada.

As lesões do ouvido medio por si só não produzem surdez bastante grave que acarrete o mutismo, mas o fechamento de ambas as janellas labyrinthicas pode produzir a surdo mudez, mesmo no caso do ouvido interno se conservar integro. 
a) $\mathrm{Na}$ surdo mudez devida a otite escarlatinosa, media e interna, notamos uma grande destruição do ouvido medio. A membrana do tympano e os ossiculos geralmente são ausentes, notando-se sempre o cholesteatoma, com carie e necrose das paredes osseas do ouvido medio. No labyrintho podemios notar uma labyrinthite suppurada chronica, a néo formação de tecido conjunctivo ou osseo, podendo ainda os espaços labyrinthicos se encontrar cheios de choles. teatona que passou atravez da janella oval. Lesões semelhantes encontramos na surdo mudez occasionada pelo sarampo.

b) Siebenmann pensa que a tuberculose do ouvido medio causando grande destruição de osso, e a consequente cicatrisação, pode acarretar a surdo mudez:

c) Em relação a lues congenita, ha dois pontos de vista quanto a natureza das alterações pathologicas. Alguns observadores pensam que a surdo mudez seja devida a meningite syphilitica, occasionando uma neuro labyrinthite secundaria, emquanto outros, pensam que ellas sejam secundaria a otite media syphilitica, commum em creanças syphiliticas, atravessando a infecção as janellas ou atacando os espaços do labyrintho, alcançando assi o ouvido interno. Esta ultima hypothese é sustentada por Moos, Steinbrugge, Gradenigo e outros.

3) Surdo mudez devida a labyrinthite consequente a meningite purulenta.

A meningite pode occorrer no periodo pré ou post natal. A meningite post natal pode ser devida a meningite cerebro espinhal epidemica ao sarampo, a pneumonia, a escarlatina a influenza, etc.

$\mathrm{O}$ processo inflamatorio começa no espaço peri-lymphatico com hyperhemia, estase, thrombose e ruptura de pequenos vasos. A isto segue-se a infiltração e necrose do endosteum. A irrigação deste é supprimida, acarretando a necrose do epithelio sensorial, com a cọagulação da endo lymphpha. O VIII par fica envolvido em puz. Mais tarde o liquido labyrin'hico torna-se purulento, havendo então completa destruição do labyrintho memb̉ranoso. Dahi resulta a formação de granulações e néo-tecido conjunctivo; mais tarde pode haver néo formação de tecido osseo. A membrana da janella redonda torna-se espessada ou rresmo calcificada, podendo a base do estribo ser deprimida para a cavidade tympanica. 
A meningite post-natal, é a mais frequente das causas da surdo mudez adquirida.

a) A maioria dos casos é devida a meningite epidemica. As "formas abortivas de meningite, acarretam profundas alterações no ouvido interno, e consequentemente a surdez. Entretanto as lesões do ouvido medio são relativamente insignificantes. Isto não se dá na surdo mudez de origem tympanica, em que constatamos profundas alterações principalmente no ouvido medio.

Nos casos de meningite as lesões mais evidentes se apresentam ao nivel da cochlea e dos canaes semi circulares. Na maioria dos casos ha ankylose do estribo na janella oval, e occlusão da janella redonda por tecido osseo.

Investigações dos centros nervosos, tem demlonstrado em taes casos, hydrocephalia chronica interna.

b) Sarampo - Reiner observou a meningite em 14 das 51 autopsias por elle feitas em casos de morte por sarampo. Nager recorda o caso de um rapaz que ficou surdo aos 3 annos, depois do sarampo, elle era lento para caminhar provavelmente devido a alterações pathologicas na macula, saccula e utricula; o exame necroscopico mostrou dilatação do labyrintho membranoso, destruição do orgão de Corti, atrophia do ganglio espiral e das fibras do nervo cochlear.

c) Escarlatina - $\mathrm{Na}$ maior parte dos casos de surdo mudez post-escarlatina ,a membrana tympanica apresenta-se normal; alguns pacientes apresentam fraqueza intelectual, tal como em outras formas de meningite.

d) Syphilis congenita - Otto Mayer examinou os ouvidos de 11 creanças syphiliticas fallecidas em periodos variando de $10 \mathrm{mli}-$ nutos a 70 mezes após o nascimento, e evidenciou alterações inflamatorias na pia mater, e na arachnoide em 10 delles. Havia tambem infiltração mieningitica ao longo do aqueducto da cochlea.

e) Labyrinthite meningitica consequente a osteo myelite $\mathrm{e}$ a diphteria. - A descripção devida a Steinbrugge de um caso de surdo mudez devido a osteo myelite, é perfeitamente semelhante a aquellas de casos de neuro labyrinthites meningitica. Siebenmann pensa que a pathologia da surdez post diphteria, seja da mesma natureza ,mas outros auctores pensam que seja devido a uma embolia infecciosa. 